\title{
Embryonic Neocortical Microglia Express Toll-Like Receptor 9 and Respond to Plasmid DNA Injected into the Ventricle: Technical Considerations Regarding Microglial Distribution in Electroporated Brain Walls
}

\author{
(D)Yuki Hattori, and (Takaki Miyata
}

https://doi.org/10.1523/ENEURO.0312-18.2018

Department of Anatomy and Cell Biology, Nagoya University Graduate School of Medicine, Nagoya 466-8550, Japan

\begin{abstract}
Microglia, the resident immune cells in the CNS, play multiple roles during development. In the embryonic cerebral wall, microglia modulate the functions of neural stem/progenitor cells through their distribution in regions undergoing cell proliferation and/or differentiation. Previous studies using CX3CR1-GFP transgenic mice demonstrated that microglia extensively survey these regions. To simultaneously visualize microglia and neurallineage cells that interact with each other, we applied the in utero electroporation (IUE) technique, which has been widely used for gene-transfer in neurodevelopmental studies, to CX3CR1-GFP mice (males and females). However, we unexpectedly faced a technical problem: although microglia are normally distributed homogeneously throughout the mid-embryonic cortical wall with only limited luminal entry, the intraventricular presence of exogenously derived plasmid DNAs induced microglia to accumulate along the apical surface of the cortex and aggregate in the choroid plexus. This effect was independent of capillary needle puncture of the brain wall or application of electrical pulses. The microglial response occurred at plasmid DNA concentrations lower than those routinely used for IUE, and was mediated by activation of Toll-like receptor 9 (TLR9), an innate immune sensor that recognizes unmethylated cytosine-phosphate guanosine motifs abundant in microbial DNA. Administration of plasmid DNA together with oligonucleotide 2088, the antagonist of TLR9, partially restored the dispersed intramural localization of microglia and significantly decreased luminal accumulation of these cells. Thus, via TLR9, intraventricular plasmid DNA administration causes aberrant distribution of embryonic microglia, suggesting that the behavior of microglia in brain primordia subjected to IUE should be carefully interpreted.
\end{abstract}

Key words: in utero electroporation; live-imaging; microglia; TLR4; TLR9; toll-like receptor

\section{Significance Statement}

Microglia have been recently shown to play multiple roles in the embryonic brain. In the trials for labeling neural-lineage cells using IUE technique in CX3CR1-GFP mice, in which microglia express GFP, to achieve dual live-imaging of these cell types, we unexpectedly found that intra-ventricular administration of plasmid DNA caused microglial aberrant accumulation along the luminal surface of the cerebral wall and in the choroid plexus. Notably, coadministration of TLR9 antagonist into the ventricle together with plasmid DNA significantly improved microglial localization in the mid-embryonic (E14) cortex, suggesting that massive microglial accumulation induced by plasmid DNA is primarily mediated by TLR9 activation. Our findings have implications for the application of IUE to investigate embryonic microglia. 


\section{Introduction}

Microglia, the resident macrophages of the CNS, are distributed throughout both adult and embryonic brain (Perry et al., 1985; Ashwell, 1991; Nimmerjahn et al., 2005; Monier et al., 2007; Swinnen et al., 2013). Embryonic microglia play multiple roles in development of neurallineage cells, e.g., phagocytotically eliminating Tbr2 ${ }^{+}$intermediate progenitors (Cunningham et al., 2013; Barger et al., 2018), regulating the differentiation status of neural progenitor cells in the subventricular zone (SVZ) and ventricular zone (VZ; Arnò et al., 2014; Hattori and Miyata, 2018), and modulating cortical interneuron positioning (Squarzoni et al., 2014; Thion and Garel, 2017). Liveimaging studies of microglia using transgenic mice such as CX3CR1-GFP mice (Jung et al., 2000) have shown that microglia dynamically change their distribution during cortical development (Swinnen et al., 2013) and extensively survey proliferative zones in response to CXCL12 during the mid-embryonic period (Hattori and Miyata, 2018).

To further investigate how microglia and neural-lineage cells interact and/or collaborate (i.e., where, when, and for how long microglia contact undifferentiated and/or intermediate neural progenitors and whether these cell types mutually influence their development), it is necessary to simultaneously live-monitor microglia and neural lineage cells and observe them under genetic manipulation. For labeling and genetic modification of neural lineage cells of embryonic mammalian brains, the in utero electroporation (IUE) technique has been widely used (Fukuchi-Shimogori and Grove, 2001; Saito and Nakatsuji, 2001; Tabata and Nakajima, 2001). Because this technique is easily combined with the use of transgenic mice developed for visualization of certain cell types or subcellular structures (Okamoto et al., 2013; Shinoda et al., 2018), we predicted that it would be useful for monitoring microglia in CX3CR1-GFP mice. In pilot trials of this dual imaging approach (i.e., visualization of both microglia and nonmicroglia), however, we unexpectedly found that conventional IUE of the embryonic mouse cerebral wall markedly altered microglial distribution in the cortex. A recent study reported that IUE caused activation of embryonic micro-

Received August 9, 2018; accepted October 27, 2018; First published November 16, 2018.

The authors declare no competing financial interests.

Author Contributions: Y.H. and T.M. designed research and wrote the paper; Y.H. performed the experiments and analyzed the data; Y.H. and T.M. approved the final version of the paper.

This work was supported by the Japan Society for the Promotion of Science (JSPS) KAKENHI Grants 16H02457 and 16K15169 (to T.M.), 16J06207 (Grantin-Aid for JSPS Fellows; to Y.H.), and 18K15003 (Grant-in-Aid for Young Scientists; to Y.H.; Y.H. is a Research Fellow of JSPS). We thank Makoto Masaoka and Namiko Noguchi (Department of Anatomy and Cell Biology, Nagoya University Graduate School of Medicine) for technical assistance.

Yuki Hattori, Department of Anatomy and Cell Biology, Nagoya University Graduate School of Medicine, 65 Tsurumai, Showa, Nagoya, Aichi, 466-8550, Japan. E-mail: ha-yuki@med.nagoya-u.ac.jp.

https://doi.org/10.1523/ENEURO.0312-18.2018

Copyright (C) 2018 Hattori and Miyata

This is an open-access article distributed under the terms of the Creative Commons Attribution 4.0 International license, which permits unrestricted use, distribution and reproduction in any medium provided that the original work is properly attributed. glia, and thus induced cell death, in the developing hypothalamus (Rosin and Kurrasch, 2018), but the underlying biological mechanisms remained unknown. In this study, we investigated the causes of abnormal microglial distribution and point to a potential molecular mechanism for this phenomenon.

\section{Materials and Methods}

\section{Mice}

CX3CR1-GFP mice (Jung et al., 2000; IMSR, Catalog \#JAX:005582; RRID:IMSR_JAX:005582) were purchased from Jackson Laboratories. ICR mice were purchased from Japan SLC. Mice were housed under specific pathogen-free conditions at Nagoya University. All protocols for animal experiments were approved by the Institutional Animal Care and Use Committee of Nagoya University. To obtain CX3CR1-GFP ${ }^{+}$embryos (heterozygous), male homozygous CX3CR1-GFP mice were mated with female ICR wild-type mice.

\section{Plasmid DNA and LPS injection into the lateral ventricle}

Plasmid DNA (pEFX2-Lyn-mCherry) purified using the QIAGEN Plasmid Maxi kit (catalog \#12163, QIAGEN) or the EndoFree Plasmid Maxi kit (catalog \#12362, QIAGEN) was dissolved in Tris-EDTA (10 mm Tris-HCl, 1 mm EDTA, $\mathrm{pH}$ 8.0) at a concentration of $5 \mu \mathrm{g} / \mu \mathrm{l}$. The plasmid stock was diluted in saline solution to a concentration of 0.5 $\mu \mathrm{g} / \mu \mathrm{l}$. To monitor injection, Fast Green $(0.1 \%)$ was added to the plasmid DNA solution at a ratio of 1:10. One microliter of plasmid DNA solution was injected into the lateral ventricle of the right hemisphere of embryonic day $(E) 12$ mouse brain. The final concentration of plasmid DNA ranged $0.03-0.5 \mu \mathrm{g} / \mu \mathrm{l}$, as indicated. After $2 \mathrm{~d}$, the number and distribution pattern of microglia were quantified in the lateral part of the cerebral wall and choroid plexus (right hemisphere; Fig. 1B). LPS (Sigma-Aldrich) was diluted in saline solution to obtain a concentration of $2.5 \mathrm{ng}$, $250 \mathrm{pg}, 25 \mathrm{pg}$, or $2.5 \mathrm{pg} / \mu \mathrm{l}$ and administered $1 \mu \mathrm{l}$ of the solution into the lateral ventricle of E12 mouse brain. Regarding the amount of bacterial endotoxin contained in plasmid DNA solution, we referred to the manufacturer's website (https://www.qiagen.com/us/resources/ technologies/plasmid-resource-center/removal\%20of\% 20bacterial\%20endotoxins/).

\section{In utero electroporation}

IUE was performed as described previously (Okamoto et al., 2013; Shinoda et al., 2018). After pregnant ICR mice were anesthetized by intraperitoneal injection of pentobarbital sodium (Somnopentyl; Kyoritsu Seiyaku), $1 \mu \mathrm{l}$ of plasmid DNA solution was injected into the lateral ventricle of E12 mouse embryos. Briefly, the head of the embryo inside the uterus was placed between the disks of a forceps-type electrode (3 mm disk electrodes for E12; CUY650P3, NEPA GENE), and electric pulses (32 V) were applied four times, resulting in gene transfection into the cerebral wall. 
A

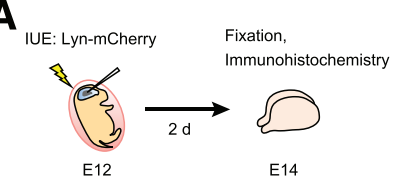

B

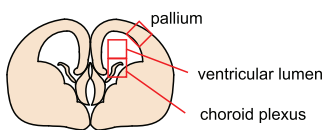

D

E apical (luminal) surface
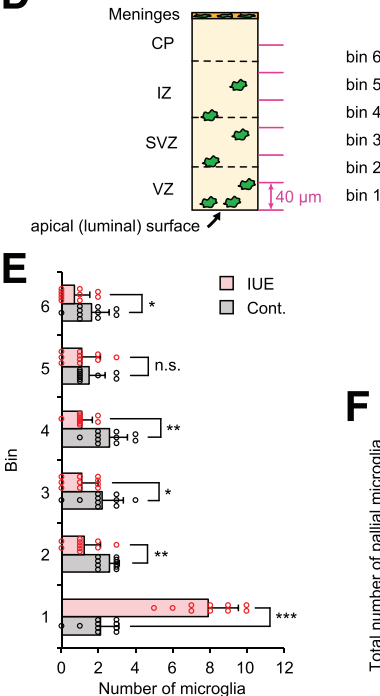

C

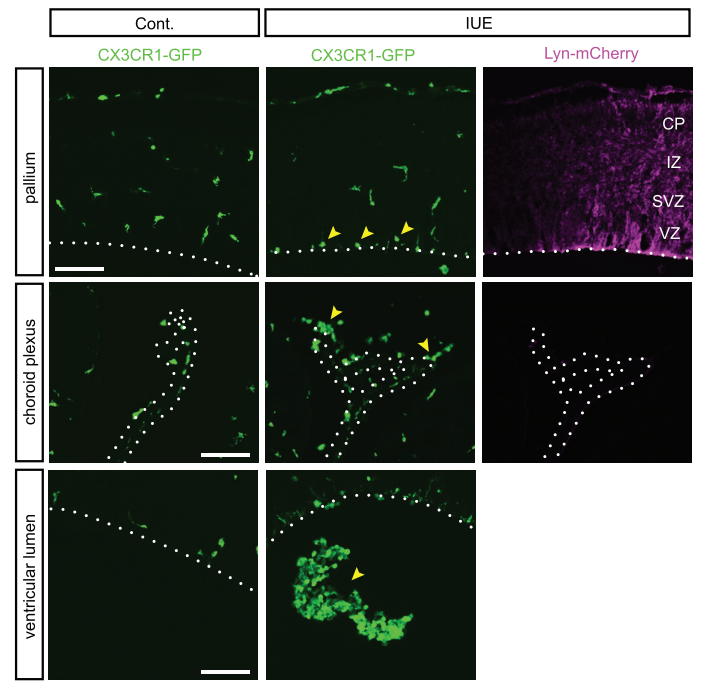

H

$\mathbf{F}$

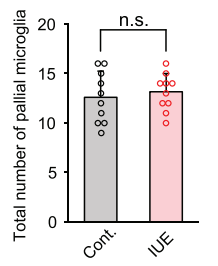

G

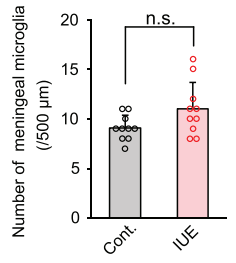

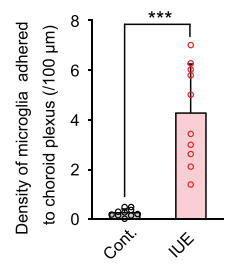

Figure 1. IUE disturbs microglial distribution in the developing cerebral cortex. $\boldsymbol{A}$, Experimental design of IUE. Plasmid DNA (pEFX2-Lyn-mCherry) was injected into the right lateral ventricle of an E12 CX3CR1-GFP mouse, and then electrical pulses were applied. After $2 \mathrm{~d}$ (E14), the brain was fixed and subjected to immunohistochemical analysis. B, Illustration showing the approximate region of pallium, choroid plexus, and ventricular lumen for immunohistochemical analyses. $\boldsymbol{C}$, Representative immunostaining to detect GFP (CX3CR1) and RFP (Lyn-mCherry) in pallium, choroid plexus, and ventricular lumen of control and IUE brains. Broken lines show the apical surface of the pallium in the top and bottom, and the choroid plexus in the middle. Yellow arrowheads indicate microglia accumulated near the apical surface of the pallium, on the choroid plexus and in the ventricular lumen. Scale bar, $100 \mu \mathrm{m}$. $\boldsymbol{D}$, Bin definition for immunohistochemical analyses is shown. Each section in the cerebral wall was numbered from the ventricle side (bins 1-6, $40 \mu \mathrm{m}$ each). $\boldsymbol{E}-\boldsymbol{G}$, Graphs depicting numbers of microglia in each bin $(40 \mu \mathrm{m} \times 300 \mu \mathrm{m}$ square; $\boldsymbol{E})$, the total number within $240 \mu \mathrm{m}$ from the apical surface of the pallium $(\boldsymbol{F})$, and the number of meningeal microglia $(\boldsymbol{G})$. $\boldsymbol{H}$, Density of microglia adhered to the choroid plexus in control versus IUE brains. For statistical analyses, $n=10$ samples obtained from five embryos ( 2 sections, each) were quantified. One or two littermates per dam were subjected to a series of tests. Data represent mean \pm SD. $* * * p<0.001$, $* * p<0.01$, $* p<0.05$, or n.s., not significant; Mann-Whitney $U$ test.

\section{Administration of TLR9 antagonist together with plasmid DNA}

Previous studies tested various oligonucleotides (ODNs) for their stimulatory or inhibitory activities for Tolllike receptor 9 (TLR9; Krieg et al., 1995; Stunz et al., 2002). Based on the finding that ODN 2088 is one of the most effective inhibitors, we applied it in our experiments as TLR9 antagonist. The ODN 2088 (5'-TCC TGG CGG GGA AGT-3') was purchased from Invivogen. The drug was suspended in endotoxin-free water and dissolved in plasmid DNA solution at a mass ratio of plasmid DNA ODN 2088 1:1. Plasmid DNA and ODN 2088 were injected into the lateral ventricles of E12 embryos. After $2 \mathrm{~d}$ (E14), the brains were perfused with 4\% PFA and subjected to immunohistochemistry.

\section{Immunohistochemistry}

Immunohistochemistry was performed as described previously (Okamoto et al., 2013). Brains were fixed in 4\%
PFA, immersed in $20 \%$ sucrose, and frozen-sections (16 $\mu \mathrm{m}$ thick) were cut. Sections were treated with the following primary antibodies: rat anti-GFP (1:500, Nacalai Tesque, catalog \#04404-84; RRID:AB_10013361) and rabbit anti-RFP (1:500, MBL, catalog \#PM005; RRID: AB_591279). After washes, sections were treated with secondary antibodies conjugated to AlexaFluor 488 (1: 400; Invitrogen, catalog \#A-11006; RRID:AB_141373) or AlexaFluor 546 (1:400; Invitrogen, catalog \#A-11010; RRID:AB_143156) and imaged on a BX60 fluorescence microscope (Olympus) or FV1000 confocal microscope (Olympus). The cerebral wall was divided into six bins (40 $\mu \mathrm{m})$ and numbered in an inside-out fashion (bins 1-6). We counted the number of microglia of which somas were within the VZ (including ones along the apical surface) but excluded microglia whose somata were completely in the ventricular lumen although they partly attached to the apical surface. 


\section{Cell sorting}

Freshly isolated pallial walls derived from E14 male and female CX3CR1-GFP mice were treated with trypsin $\left(0.05 \%, 3 \mathrm{~min}\right.$ at $\left.37^{\circ} \mathrm{C}\right)$. Dissociated pallial cells were filtered through a $40 \mu \mathrm{m}$ strainer (Corning) to eliminate all remaining cell clumps, and then resuspended in DMEM containing 5\% fetal bovine serum (Invitrogen), 5\% horse serum (Invitrogen), and penicillin/streptomycin $(50 \mathrm{U} / \mathrm{ml}$, each; Meiji Seika Pharma). CX3CR1-GFP ${ }^{+}$cells were sorted through a 100- $\mu \mathrm{m}$ nozzle by FACS Aria II (BD Biosciences). The drop delay was optimized using $B D$ Biosciences Accudrop beads (BD Biosciences).

\section{Real-time PCR}

First-strand cDNA was synthesized from $\sim 100 \mathrm{ng}$ total RNA was reverse-transcribed into cDNA using SuperScript III reverse transcriptase (ThermoFisher Scientific) in the presence of RNase inhibitor (Thermo Fisher Scientific). Real-time PCR was performed with SYBR Green Real Time PCR Master (Toyobo) using Thermal Cycler Dice Real Time System TP800 (TaKaRa). To amplify specific transcripts, samples were heated at $95^{\circ} \mathrm{C}$ for $15 \mathrm{~min}$ and subsequently underwent a melting curve analysis from $60^{\circ} \mathrm{C}$ to $95^{\circ} \mathrm{C}$. The threshold cycle number $(\mathrm{Ct})$ of the target was calculated and expressed relative to that of GAPDH, and then $\Delta \Delta C t$ values of the target were calculated and presented as relative fold induction. Primers were: 5'-AGC CTC CGA GAC AAC TAC CT-3' (sense) and 5'-TTG GTC AGG GCC TTT AGC TG-3' (antisense) for TLR9; 5'-TCC CTG CAT AGA GGT AGT TCC TA-3' (sense) and 5'-TTC AAG GGG TTG AAG CTC AGA-3' (antisense) for TLR4; and 5'-GTT GTC TCC TGC GAC TTC A-3' (sense) and 5'-GGT GGT CCA GGG TTT CTT A-3' (antisense) for GAPDH.

\section{Live imaging in cortical slice culture}

To obtain cortical slices covered with intact meninges, whole forebrains isolated from E14 male and female CX3CR1-GFP mice that had been electroporated at E12 were embedded in $2 \%$ agarose gel, and then sliced coronally $(350 \mu \mathrm{m})$ using a vibratome. The slices were cultured in collagen gel as previously described (Miyata et al., 2004). Time-lapse imaging was performed on a CV1000 confocal microscope (Olympus). Chambers for on-stage culture were filled with $40 \% \mathrm{O}_{2}$.

\section{Statistical analysis}

Quantitative data are presented as mean \pm SD from representative experiments. Statistical differences between groups were analyzed by Mann-Whitney $U$ test for two-group comparisons or Steel-Dwass test for multiple comparisons using $\mathrm{R}$ software. $p<0.05$ was considered significant. $p$ values in every figure are separately listed in tables (Tables 1-7). Individual values were plotted as open circles in bar graphs. The number of samples examined in each analysis is shown in the figure legends.
Table 1. Statistics for Figure 1

\section{Graph Data structure Type of test}

Fig. $1 E$ Nonparametric Mann-Whitney $U$ test Bin $1: 1.1 \times 10^{-5}$

Bin 2: 0.0022

Bin 3: 0.0307

Bin 4: 0.0014

Bin 5: 0.4281

Bin 6: 0.0495

Fig. $1 F$ Nonparametric Mann-Whitney $U$ test 0.6835

Fig. $1 G$ Nonparametric Mann-Whitney $U$ test 0.1021

Fig. $1 H$ Nonparametric Mann-Whitney $U$ test $1.1 \times 10^{-5}$

\section{Results}

\section{IUE disturbs microglial distribution in the developing} cerebral cortex

To simultaneously visualize microglia and neurallineage cells, we performed IUE on E12 CX3CR1-GFP mice (Jung et al., 2000). Briefly, plasmid DNA (pEFX2-LynmCherry) was injected into the lateral ventricle of the right hemisphere of E12 mouse brain using a glass capillary needle, followed by electrical pulses across the embryo's head (Fig. 1A). Surprisingly, immunohistochemical inspections $2 \mathrm{~d}$ later revealed that the distribution patterns of $\mathrm{CX} 3 \mathrm{CR} 1^{+}$microglia in the pallium and choroid plexus were abnormal (Fig. 1B,C). Normally at E14, microglia are distributed diffusely throughout the pallium along the radial (ventricle-to-pia) axis, and are found in the VZ, SVZ, and intermediate zone (IZ; Perry et al., 1985; Ashwell, 1991; Monier et al., 2007; Cunningham et al., 2013; Swinnen et al., 2013). In brains subjected to IUE (hereafter, IUE brains), however, microglia were extremely scarce in both the SVZ and IZ (bins 2-4) and aberrantly accumulated along the apical surface (within $40 \mu \mathrm{m}$ from the apical surface: bin 1; Fig. 1C-E; Table 1), with the total number of microglia in the pallium and meningeal microglia comparable between control (non-IUE) and IUE brains (Fig. $1 F, G)$. IUE brains also exhibited densely accumulated microglia in the choroid plexus and the ventricle, whereas no such massive luminal infiltrations were observed in non-IUE controls (Fig. 1C,H). IUE caused the same type of aberrant microglial distribution in wild-type (ICR, nonCX3CR1-GFP transgenic) mice (data not shown). These results indicate that, in our hands, the standard IUE technique disturbed the localization of microglia in a manner suggestive of an attraction from the IZ or SVZ toward the ventricular lumen.

\section{Plasmid DNA injection into the ventricle, without electrical pulses, results in abnormal microglial distribution}

To determine which of the steps involved in IUE (1, puncturing the cerebral wall with a glass capillary needle; 2 , injection of plasmid vector DNA into the lateral ventricle; 3 , electrical pulses) causes microglial aberrant accumulation, we compared the distribution of microglia between embryos subjected to each of these procedures separately. When the cerebral wall was only punctured with a glass capillary needle, but no solution was injected, microglia were still distributed homogenously throughout the cortex, as in control (nontreated) brains (Fig. $2 A-D$; 


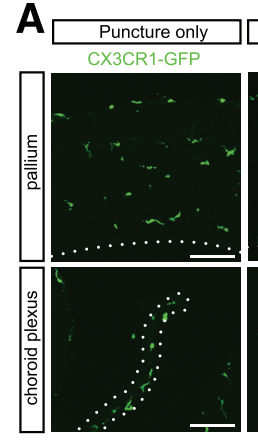

B

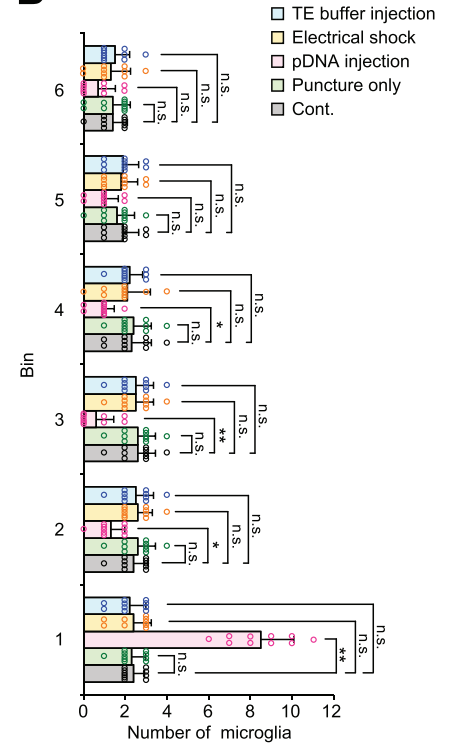

$\stackrel{5}{\text { ติ }}$

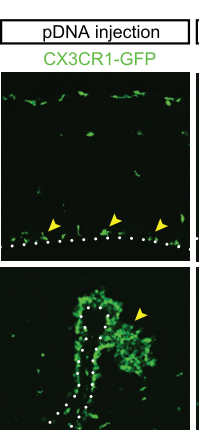

TE buffer injection $\square$ Electrical shock $\square$ pDNA injection $\square$ Puncture only

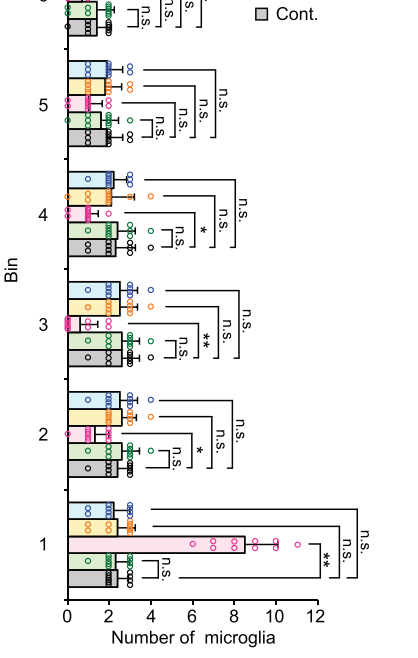

\section{D}

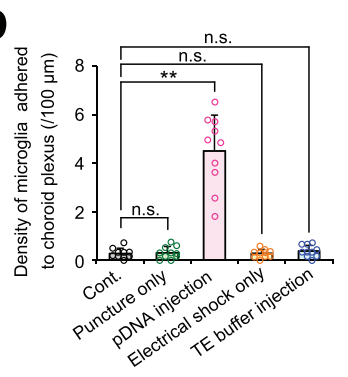

Figure 2. Plasmid DNA injection into the ventricle, without electrical pulses, results in abnormal microglial distribution. $\boldsymbol{A}$, Representative immunostaining for CX3CR1-GFP in the pallium and choroid plexus of mouse brains subjected to puncture with a glass capillary needle, injection of plasmid DNA (shown as pDNA) into the lateral ventricle, electrical pulses, or injection of Tris-EDTA solution (10 mm Tris-HCl, 1 mm EDTA, pH 8.0) alone without plasmid DNA. Yellow arrowheads indicate microglia accumulated near the apical surface of the cerebral wall or adhered to the choroid plexus. Broken lines show the apical surface of the pallium in the top and the choroid plexus in the bottom. Scale bar, $100 \mu \mathrm{m}$. B, C, Graphs depicting the number of microglia positioned in each $40 \mu \mathrm{m}$ bin $(\boldsymbol{B})$ and the total number of these cells within $240 \mu \mathrm{m}$ from the apical surface $(\boldsymbol{C})$ in brains that were subjected to each procedure. $\boldsymbol{D}$, Density of microglia adhered to the choroid plexus. For statistical analyses, $n=10$ samples obtained from five embryos (2 sections, each) were quantified. One or two littermates per dam were subjected to a series of tests. Data represent mean \pm SD. $* * * p<0.001$, $* * p<0.01, * p<0.05$, or n.s., not significant; Steel-Dwass test.

Table 2). By contrast, brains that were intraventricularly injected with plasmid DNA (pEFX2-Lyn-mCherry) but not subjected to electrical pulses exhibited massive microglial accumulation near the ventricle in the VZ and their infiltration in the choroid plexus. On the other hand, electrical pulses alone did not result in aberrant microglial distribution. In another control group injected with Tris-EDTA solution (10 mm Tris-HCl, $1 \mathrm{~mm}$ EDTA, $\mathrm{pH}$ 8.0) alone,

microglia showed normal distribution pattern in the cerebral wall and did not aggregate in the choroid plexus (Fig. $2 A-D)$. These results strongly suggest that the presence of exogenously sourced plasmid DNAs in embryonic mouse ventricle caused abnormal microglial distribution.

\section{Timing and sensitivity of microglial response to intraventricularly injected plasmid DNAs}

Next, we sought to determine the sensitivity of intramural microglia to intraventricular plasmid DNAs. To compare the threshold amount of DNA required to provoke microglial responses with the amounts of DNA used in standard IUE protocols $(0.5-1.0 \mu \mathrm{g}$ per unilateral ventricular space; Okamoto et al., 2013; Shinoda et al., 2018), we injected solutions containing various amounts of pEFX2Lyn-mCherry $(0.25,0.13,0.06$, and $0.03 \mu \mathrm{g})$ into the lateral ventricles of E12 embryos. After 2 d (E14), microglial accumulation near the ventricle was still observed in brains injected with $0.25,0.13$, or $0.06 \mu \mathrm{g}$ plasmid DNA (Fig. 3A,B; Table 3), with no increase of the total number of pallial microglia (Fig. $3 C$ ). We also found dosedependent accumulation of microglia in the choroid plexus (Fig. 3D). By contrast, in brains injected with 0.03 $\mu \mathrm{g}$ plasmid DNA, microglia were observed in a normal pattern (widely distributed from the VZ to IZ) with no accumulation in the choroid plexus. These results showed that amounts of plasmid DNA much smaller than those conventionally used for IUE can cause microglia to infiltrate toward and in the ventricular lumen.

To determine how quickly microglia infiltrate into the DNA-injected lumen, we analyzed E14 brains soon (4 h) after administration of plasmid DNA solution $(0.5 \mu \mathrm{g}$ plasmid DNA), and found that the distribution of microglia was already abnormal. Specifically, microglia had departed from their original locations (the IZ, SVZ, and upper VZ) toward the apical surface (Fig. 4A,B; Table 4), although they had not yet accumulated in the choroid plexus (Fig. $4 A, C)$. The total number of pallial microglia was comparable between plasmid DNA-treated and control brains (Fig. 4D). These results suggest that intramural microglia can immediately sense plasmid DNAs injected into the ventricle, leading to a change in their regional distribution.

\section{Intraventricular administration of TLR9 antagonist decreases microglial infiltration induced by plasmid DNA injection}

Macrophages, including microglia, express TLRs, prototype pattern-recognition receptors (PRRs) that recognize pathogen-associated molecular patterns (PAMPs) from microorganisms and thus initiate innate immune responses after viral or bacterial infection (Akira and Takeda, 2004; Takeuchi and Akira, 2010; O'Neill et al., 2013; Vijay, 2018). Among these receptors, TLR9 recognizes unmethylated CpG motifs, which are characteristic of bacterial and viral DNAs (Krieg et al., 1995; Hemmi et al., 2000; Bauer et al., 2001; Kumagai et al., 2008). TLR9 is expressed in microglia in the postnatal and adult brain (Doi et al., 2009; Butchi et al., 2011; Christensen et al., 2014; Matsuda et al., 2015; Cho and Hsieh, 2016; Scholtzova et al., 2017). Within cells, TLR9 primarily resides in the intracellular compartment (i.e., late-endo- 
Table 2. Statistics for Figure 2

\begin{tabular}{lll}
\hline Graph & Data structure & Type of test \\
Fig. $2 B$, bin 1 & Nonparametric & Steel-Dwass
\end{tabular}

Steel-Dwass

Fig. $2 B$, bin 2

Nonparametric

Steel-Dwass

Fig. $2 B$, bin 3

Nonparametric

Steel-Dwass

Fig. $2 B$, bin 4

Nonparametric

Steel-Dwass

Fig. $2 B$, bin 5

Nonparametric

Steel-Dwass

Fig. $2 B$, bin 6

Nonparametric

Steel-Dwass

Fig. $2 C$

Nonparametric

Steel-Dwass

Fig. 2D

Nonparametric Steel-Dwass

\section{p}

Cont vs Puncture only, $p=0.9990$;

Cont vs pDNA injection, $p=0.0011$;

Cont vs Electrical shock only, $p=0.9973$;

Cont vs TE buffer injection, $p=0.9871$

Cont vs Puncture only, $p=0.9781$;

Cont vs pDNA injection, $p=0.0369$;

Cont vs Electrical shock only, $p=0.9937$;

Cont vs TE buffer injection, $p=0.9996$

Cont vs Puncture only, $p=1.0000$;

Cont vs pDNA injection, $p=0.0055$;

Cont vs Electrical shock only, $p=0.9976$;

Cont vs TE buffer injection, $p=0.9976$

Cont vs Puncture only, $p=0.9992$;

Cont vs pDNA injection, $p=0.0154$;

Cont vs Electrical shock only, $p=0.9964$;

Cont vs TE buffer injection, $p=0.9996$

Cont vs Puncture only, $p=0.9473$;

Cont vs pDNA injection, $p=0.1056$;

Cont vs Electrical shock only, $p=0.9976$;

Cont vs TE buffer injection, $p=1.0000$

Cont vs Puncture only, $p=0.9998$;

Cont vs pDNA injection, $p=0.3261$;

Cont vs Electrical shock only, $p=0.9962$;

Cont vs TE buffer injection, $p=1.0000$

Cont vs Puncture only, $p=0.9994$;

Cont vs pDNA injection, $p=1.0000$;

Cont vs Electrical shock only, $p=0.9969$;

Cont vs TE buffer injection, $p=0.9981$

Cont vs Puncture only, $p=0.9989$;

Cont vs pDNA injection, $p=0.0015$;

Cont vs Electrical shock only, $p=0.9994$;

Cont vs TE buffer injection, $p=0.9913$ some/lysosome) and binds to $\mathrm{CpG}$ motifs after internalization of microbial DNA (Takeshita et al., 2001; Ahmad-Nejad et al., 2002; Barton et al., 2006; Chockalingam et al., 2009). Hence, we investigated whether plasmid DNA (usually produced in Escherichia coli) might evoke innate immune responses in microglia via TLR9.

To determine whether embryonic microglia express TLR9, we performed real-time quantitative PCR on CX3CR1-GFP ${ }^{+}$microglia and CX3CR1-GFP- cells (most of which are of the neural lineage) isolated by cell sorting from the cortical wall of E14 CX3CR1-GFP mice. CX3CR $1^{+}$microglia expressed 529-fold higher level of TLR9 compared with CX3CR $1^{-}$cells $(p=0.0286$, MannWhitney $U$ test; Fig. 5A).

Next, to investigate whether microglial accumulation caused by plasmid DNA administration was mediated by TLR9, we coinjected ODN 2088, an inhibitory oligonucleotide that acts as a TLR9 antagonist (Stunz et al., 2002), into the mouse ventricle along with plasmid DNA (0.5 $\mu \mathrm{g}$; Fig. 5B). ODN 2088 treatment partially restored the number of microglia localized in the SVZ/IZ and significantly reduced their accumulation along the apical surface, although it did not entirely rescue abnormal distribution [the number of microglia in bin 1 was still higher than control (nontreated) or only ODN 2088-treated brains; Fig. 5C,D; Table 5]. In addition, microglial infiltration in the choroid plexus was significantly reduced in ODN 2088-treated brains but still greater than control groups (Fig. 5E). On the other hand, the total number of microglia in the cortex was comparable between brains injected with plasmid DNA alone and those coinjected with plasmid DNA and ODN 2088 (Fig. 5F). Together, these results suggest that microglia expressing TLR9 may sense intraventricularly injected plasmid DNA and subsequently accumulate near the apical surface in the VZ and in the choroid plexus. Furthermore, we confirmed that performing IUE with LynmCherry vector in the presence of ODN 2088 enabled us to prepare fresh slice cultures in which CX3CR1-GFP ${ }^{+}$ microglia were almost normally distributed and neurallineage cells were labeled red (Fig. 5G; Movies 1 and 2).

\section{Endotoxins, if contained in plasmid DNA solution, trigger microglial aberrant accumulation}

Although ODN 2088 treatment partially improved microglial distribution in the embryonic brain, microglia still accumulated near the apical surface of the cerebral wall. We postulated that the presence of bacterial endotoxin, lipopolysaccharide (LPS), in plasmid preparations might influence embryonic microglia. Because $\mathrm{CX} 3 \mathrm{CR} 1^{+}$microglia derived from E14 cerebral wall expressed TLR4, a receptor for LPS (Akira and Takeda, 2004), much higher (290-fold higher level) than CX3CR1- neural lineage cells $(p=0.0286$, Mann-Whitney $U$ test; Fig. $6 A)$, we wanted to test whether LPS might elicit microglial activation in a separate manner from TLR9 signaling, and also determine 


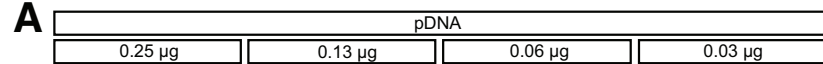

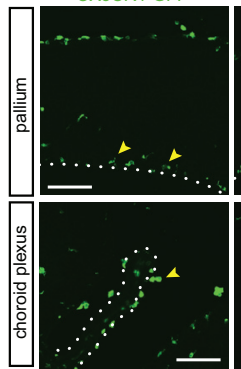

B

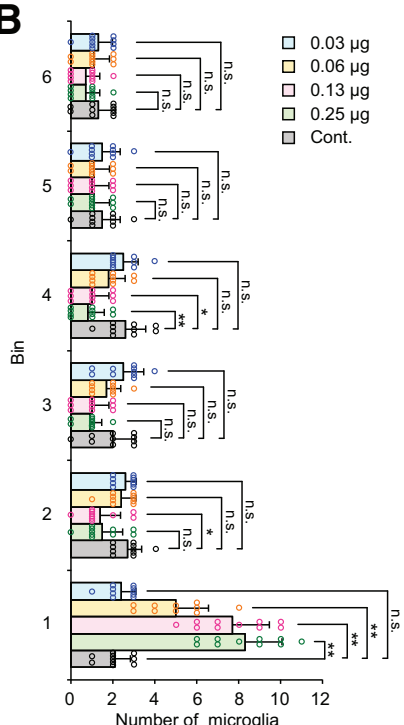

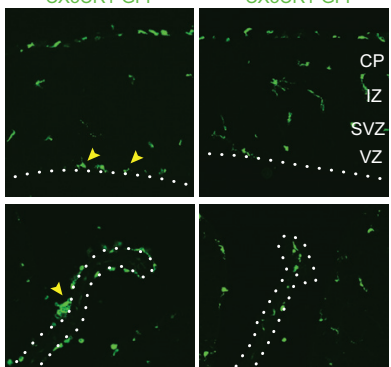

C

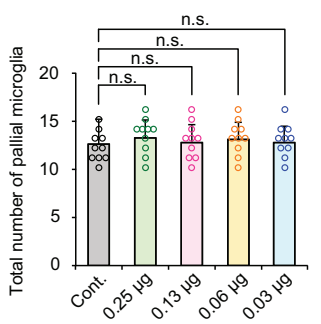

D

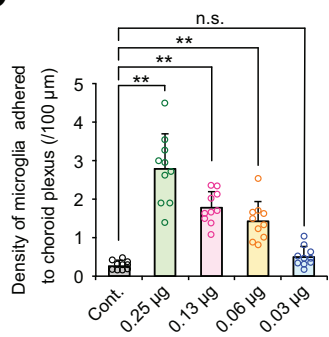

Figure 3. Sensitivity of microglial response to intraventricularly injected plasmid DNAs. A, CX3CR1-GFP immunostaining showing microglial accumulation in brains injected with the indicated amount of plasmid DNA $(0.25,0.13,0.06$, and $0.03 \mu \mathrm{g})$. Yellow arrowheads indicate microglia accumulated near the apical surface of the pallium and on the choroid plexus. Scale bar, $100 \mu \mathrm{m} . \boldsymbol{B}, \boldsymbol{C}$, Graphs depicting the number of microglia positioned in each $40 \mu \mathrm{m}$ bin $(\boldsymbol{B})$ and the total number of these cells within $240 \mu \mathrm{m}$ from the apical surface $(\boldsymbol{C})$ in brains that were injected with plasmid DNA. $\boldsymbol{D}$, Density of microglia adhered to the choroid plexus. For statistical analyses, $n=10$ samples obtained from five embryos (2 sections, each) were quantified. One or two littermates per dam were subjected to a series of tests. Data represent mean \pm SD. $* * * p<0.001, * * p<0.01$, *p $<0.05$, or n.s., not significant; Steel-Dwass test.

how much LPS would be required to cause microglial abnormal localization.

Our routine preparations of plasmid (QIAGEN Plasmid Maxi Kit) for IUE yields relatively pure DNA with low levels of endotoxin $[9.3$ endotoxin unit $(E U) / \mu$ g plasmid DNA; typically, 1 ng LPS corresponds to 1-10 EU, e.g., 0.47$4.7 \mathrm{ng}$ LPS is estimated to be contained per $0.5 \mu \mathrm{g}$ plasmid DNA]. When LPS alone diluted in saline was injected into the lateral ventricles of E12 embryos, immunohistochemistry after $2 \mathrm{~d}$ (at E14) demonstrated that, in brains treated with $2.5 \mathrm{ng}, 250 \mathrm{pg}$, and $25 \mathrm{pg}$ LPS, microglia were abnormally distributed (Fig. 6B-D; Table 6), which was coupled with an increase of the total number of pallial microglia in $2.5 \mathrm{ng}$ LPS-treated cases

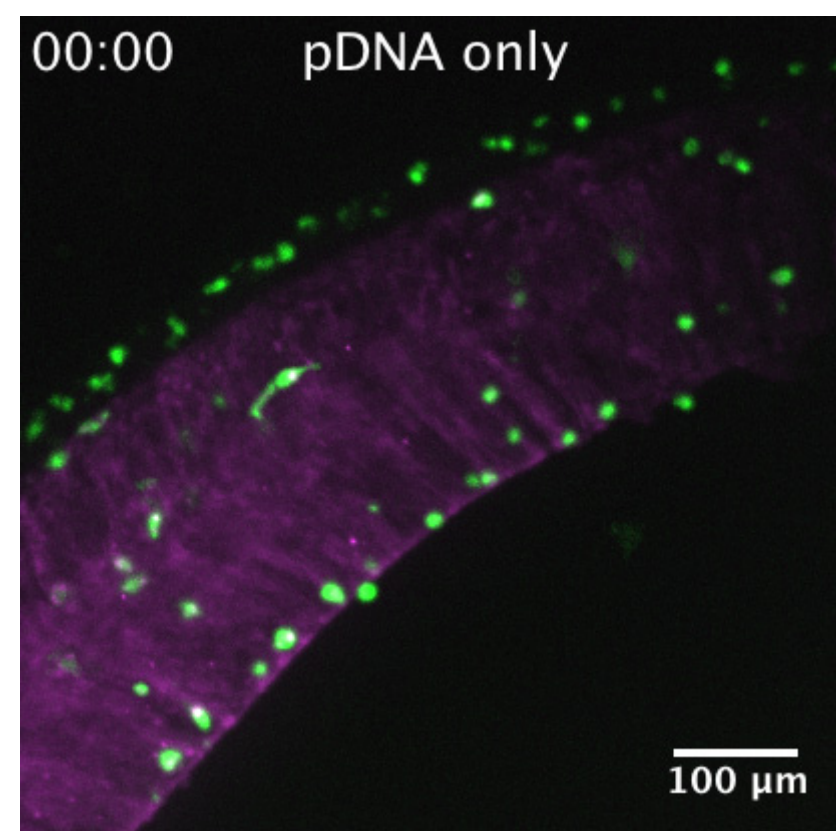

Movie 1. Live-imaging of microglia in plasmid DNA-treated brains. Live imaging of microglia in a cortical slice derived from a CX3CR1-GFP mouse brain transfected with Lyn-mCherry. Time-lapse imaging covers a period of $10 \mathrm{~h}$ (1 image/10 min). Green, CX3CR1-GFP; magenta, Lyn-mCherry. Scale bar, 100 $\mu \mathrm{m}$. [View online]

(Fig. 6E). On the other hand, microglia showed normal localization in brains exposed to $2.5 \mathrm{pg}$ LPS. This indicates that much lower levels of LPS than that contained in

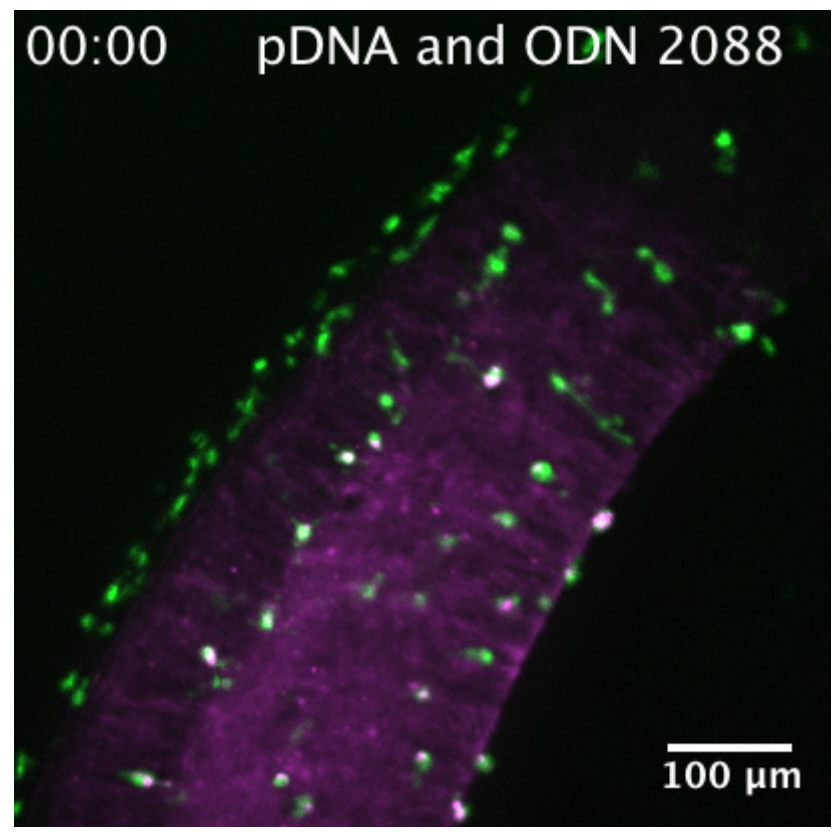

Movie 2. Live-imaging of microglia in plasmid DNA and ODN 2088 coinjected brains. Live imaging of microglia in a cortical slice derived from a CX3CR1-GFP mouse brain transfected LynmCherry with coadministration of ODN 2088. Time-lapse imaging covers a period of $10 \mathrm{~h}$ (1 image/10 min). Green, CX3CR1GFP; magenta, Lyn-mCherry. Scale bar, $100 \mu \mathrm{m}$. [View online] 
Table 3. Statistics for Figure 3

\begin{tabular}{lll}
\hline Graph & Data structure & Type of test \\
Fig. $3 B$, bin 1 & Nonparametric & Steel-Dwas
\end{tabular}

Steel-Dwass

Steel-Dwass

Fig. $3 B$, bin 2

Nonparametric

Nonparametric

Steel-Dwass

Fig. $3 B$, bin 3

Nonparametric

Steel-Dwass

Fig. $3 B$, bin 4

Nonparametric

Steel-Dwass

Fig. $3 B$, bin 5

Nonparametric

Steel-Dwass

Fig. $3 B$, bin 6

Nonparametric

Steel-Dwass

Fig. $3 C$

Nonparametric

Steel-Dwass

\section{p}

Cont vs $0.25 \mu \mathrm{g}, p=0.0013$;

Cont vs $0.13 \mu \mathrm{g}, p=0.0013$;

Cont vs $0.06 \mu \mathrm{g}, p=0.0028$;

Cont vs $0.03 \mu \mathrm{g}, p=0.8787$

Cont vs $0.25 \mu \mathrm{g}, p=0.0693$;

Cont vs $0.13 \mu \mathrm{g}, p=0.0453$;

Cont vs $0.06 \mu \mathrm{g}, p=0.9317$;

Cont vs $0.03 \mu \mathrm{g}, p=0.9990$

Cont vs $0.25 \mu \mathrm{g}, p=0.1044$;

Cont vs $0.13 \mu \mathrm{g}, p=0.2141$;

Cont vs $0.06 \mu \mathrm{g}, p=0.8898$;

Cont vs $0.03 \mu \mathrm{g}, p=0.8352$

Cont vs $0.25 \mu \mathrm{g}, p=0.0098$;

Cont vs $0.13 \mu \mathrm{g}, p=0.0196$;

Cont vs $0.06 \mu \mathrm{g}, p=0.3581$;

Cont vs $0.03 \mu \mathrm{g}, p=0.9985$

Cont vs $0.25 \mu \mathrm{g}, p=0.8286$;

Cont vs $0.13 \mu \mathrm{g}, p=0.7255$;

Cont vs $0.06 \mu \mathrm{g}, p=0.8286$;

Cont vs $0.03 \mu \mathrm{g}, p=1.0000$

Cont vs $0.25 \mu \mathrm{g}, p=0.4412$;

Cont vs $0.13 \mu \mathrm{g}, p=0.4412$

Cont vs $0.06 \mu \mathrm{g}, p=0.9667$;

Cont vs $0.03 \mu \mathrm{g}, p=0.9999$

Cont vs $0.25 \mu \mathrm{g}, p=0.6147$;

Cont vs $0.13 \mu \mathrm{g}, p=0.9493$

Cont vs $0.06 \mu \mathrm{g}, p=0.7574$

Cont vs $0.03 \mu \mathrm{g}, p=0.9162$

Cont vs $0.25 \mu \mathrm{g}, p=0.0015$;

Cont vs $0.13 \mu \mathrm{g}, p=0.0015$

Cont vs $0.06 \mu \mathrm{g}, p=0.0015$;

Cont vs $0.03 \mu \mathrm{g}, p=0.1825$ plasmid DNA solution to be used for IUE may substantially trigger microglial response.

We tested plasmid DNAs purified using a commerciallysourced endotoxin-free $(<0.1 \mathrm{EU} / \mu \mathrm{g}$ plasmid DNA) protocol according to manufacturer's instructions (QIAGEN EndoFree Plasmid Maxi Kit). Similar to ones purified with the QIAGEN Plasmid Maxi Kit, the endotoxin-free DNAs $(0.5,0.25 \mu \mathrm{g})$ caused microglial aberrant distribution without an increase of the total number (Fig. 7A-D; Table 7), but endotoxin-free plasmid DNA did not evoke microglial responses at $0.13 \mu \mathrm{g}$, which was $>0.03 \mu \mathrm{g}$, a dose for DNAs obtained with the QIAGEN Plasmid Maxi Kit which would have contained more endotoxin (Fig. 3). Of note, improvements in the localization of pallial microglia were much more clearly seen when ODN 2088 was coadministrated with endotoxin-free plasmid DNAs $(0.5 \mu \mathrm{g})$ than used with endotoxin-containing ones (Fig. 7E-H; Table 7; Fig. 7-1), with a minor microglial infiltration in the choroid plexus (Fig. 7l; Fig. 7-2).

Together, these results strongly suggest that although endotoxin can also disturb microglial distribution, plasmid DNA itself is the major inducer of abnormal distribution of the mid-embryonic (E14) cortical microglia through their activation of TLR9.

\section{Discussion}

Here, we showed that injection of plasmid DNA into the lateral ventricle for IUE induced microglia to accumulate near the luminal surface and aggregate in the choroid plexus, even if electrical pulses were not applied. Notably, this aberrant distribution was triggered through recognition of plasmid DNA by TLR9 expressed in microglia (Fig. 8). Consistent with this, coinjection of a TLR9 antagonist into the ventricle along with plasmid DNA significantly restored the normal, dispersed localization pattern of microglia.

Given that plasmid DNA injection changed the intramural distribution of microglia without changing the total number of microglia per cerebral wall, it is most likely that the observed disappearance of microglia from the $\mathrm{IZ}$ and SVZ and their accumulation along the ventricular surface were due to ventricle-directed migration. However, our results do not exclude the possibility that peripheral macrophages infiltrated the embryonic brain, as was very recently shown to occur in response to IUE (Rosin and Kurrasch, 2018). Peripheral macrophage infiltration might underlie the microglial accumulation in the choroid plexus observed in this study. Nevertheless, it is unclear how deeply plasmid DNAs diffuse into the brain wall. We speculate that intra-VZ microglia primarily receive the DNAs and then release certain factors (i.e., cytokines and/or chemokines) that attract other microglia in the IZ or SVZ. Indeed, Rosin and Kurrasch (2018) showed that inflammatory cytokines and chemokines [such as tumor necrosis factor alpha (TNF- $\alpha)$, interleukin- $1 \beta$ (IL-1 $\beta)$, IL-6, 
A
B

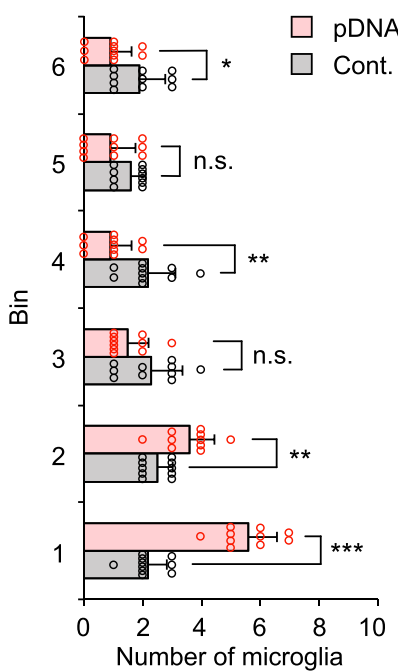

D

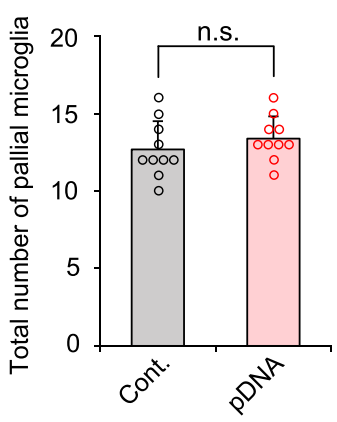

Figure 4. Microglia immediately sense plasmid DNAs injected into the ventricle. $\boldsymbol{A}$, Representative immunostaining of CX3CR1GFP in E14 brain fixed soon (4 h) after administration of $0.5 \mu \mathrm{g}$ plasmid DNA. Yellow arrowheads show microglia accumulated near the apical surface of the pallium and on the choroid plexus. Scale bar, $100 \mu \mathrm{m}$. B, Graph showing the number of pallial microglia positioned in each $40 \mu \mathrm{m}$ bin in control and plasmid-injected brains. $\boldsymbol{C}$, Graph comparing density of microglia adhered to choroid plexus. $\boldsymbol{D}$, The total number of pallial microglia within $240 \mu \mathrm{m}$ from the apical surface. For statistical analyses, $n=10$ samples obtained from five embryos (2 sections, each) were quantified. Two or three littermates per dam were subjected to a series of tests. Data represent mean \pm SD. $* * * p<0.001$, $* * p<0.01, * p<$ 0.05 , or n.s., not significant; Mann-Whitney $U$ test.

Table 4 Statistics for Figure 4

\begin{tabular}{|c|c|c|c|}
\hline Graph & Data structure & Type of test & $p$ \\
\hline Fig. $4 B$ & Nonparametric & Mann-Whitney $U$ & $\begin{array}{l}\text { bin } 1: 1.1 \times 10^{-5} \\
\text { bin 2: } 0.0074 \\
\text { bin 3: } 0.1023 \\
\text { bin 4: } 0.0058 \\
\text { bin 5: } 0.0837 \\
\text { bin 6: } 0.0275\end{array}$ \\
\hline Fig. $4 C$ & Nonparametric & Mann-Whitney $U$ & 0.9869 \\
\hline Fig. $4 D$ & Nonparametric & Mann-Whitney $U$ & 0.2789 \\
\hline
\end{tabular}

Table 5 Statistics for Figure 5

\begin{tabular}{|c|c|c|c|}
\hline Graph & Data structure & Type of test & $p$ \\
\hline Fig. $5 D$, bin 1 & Nonparametric & Steel-Dwass & $\begin{array}{l}\text { Cont vs ODN } 2088, p=0.8335 \\
\text { Cont vs pDNA, } p=5.6 \times 10^{-6} ; \\
\text { pDNA vs. pDNA + ODN 2088, } p=2.4 \times 10^{-4} \\
\text { Cont vs pDNA + ODN } 2088, p=2.1 \times 10^{-5}\end{array}$ \\
\hline Fig. $5 D$, bin 2 & Nonparametric & Steel-Dwass & $\begin{array}{l}\text { Cont vs ODN } 2088, p=0.6401 \\
\text { Cont vs pDNA, } p=1.3 \times 10^{-5} ; \\
\text { pDNA vs. pDNA + ODN 2088, } p=0.0627 \\
\text { Cont vs pDNA + ODN } 2088, p=0.0163\end{array}$ \\
\hline Fig. $5 D$, bin 3 & Nonparametric & Steel-Dwass & $\begin{array}{l}\text { Cont vs ODN } 2088, p=0.9781 \\
\text { Cont vs pDNA, } p=8.2 \times 10^{-5} ; \\
\text { pDNA vs. pDNA + ODN 2088, } p=4.7 \times 10^{-4} \\
\text { Cont vs pDNA + ODN 2088, } p=0.5691\end{array}$ \\
\hline Fig. $5 D$, bin 4 & Nonparametric & Steel-Dwass & $\begin{array}{l}\text { Cont vs ODN } 2088, p=0.9746 \\
\text { Cont vs pDNA, } p=0.0102 ; \\
\text { pDNA vs. pDNA + ODN 2088, } p=0.1967 \\
\text { Cont vs pDNA + ODN 2088, } p=0.3568\end{array}$ \\
\hline Fig. $5 D$, bin 5 & Nonparametric & Steel-Dwass & $\begin{array}{l}\text { Cont vs ODN 2088, } p=0.9276 \\
\text { Cont vs pDNA, } p=0.0610 ; \\
\text { pDNA vs. pDNA + ODN 2088, } p=0.7661 \text {; } \\
\text { Cont vs pDNA + ODN 2088, } p=0.5053\end{array}$ \\
\hline Fig. $5 D$, bin 6 & Nonparametric & Steel-Dwass & $\begin{array}{l}\text { Cont vs ODN 2088, } p=0.9955 \\
\text { Cont vs pDNA, } p=0.9158 ; \\
\text { pDNA vs. pDNA + ODN 2088, } p=0.7539 \\
\text { Cont vs pDNA + ODN 2088, } p=0.9840\end{array}$ \\
\hline Fig. $5 E$ & Nonparametric & Steel-Dwass & $\begin{array}{l}\text { Cont vs ODN } 2088, p=0.8121 \\
\text { Cont vs pDNA, } p=8.4 \times 10^{-6} ; \\
\text { pDNA vs. pDNA + ODN 2088, } p=0.0374 ; \\
\text { Cont vs pDNA + ODN 2088, } p=8.4 \times 10^{-6}\end{array}$ \\
\hline Fig. $5 F$ & Nonparametric & Steel-Dwass & $\begin{array}{l}\text { Cont vs ODN } 2088, p=0.9966 \\
\text { Cont vs pDNA, } p=0.9982 ; \\
\text { pDNA vs. pDNA + ODN 2088, } p=0.6688 \\
\text { Cont vs pDNA + ODN 2088, } p=0.7716\end{array}$ \\
\hline
\end{tabular}


A

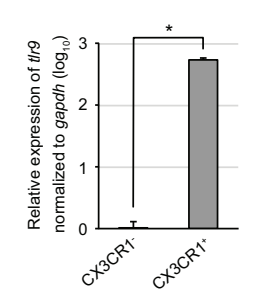

B

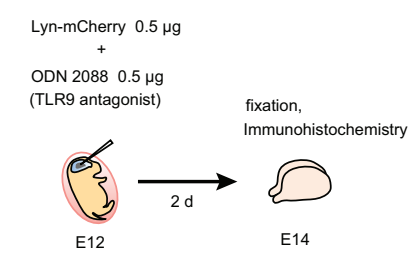

C

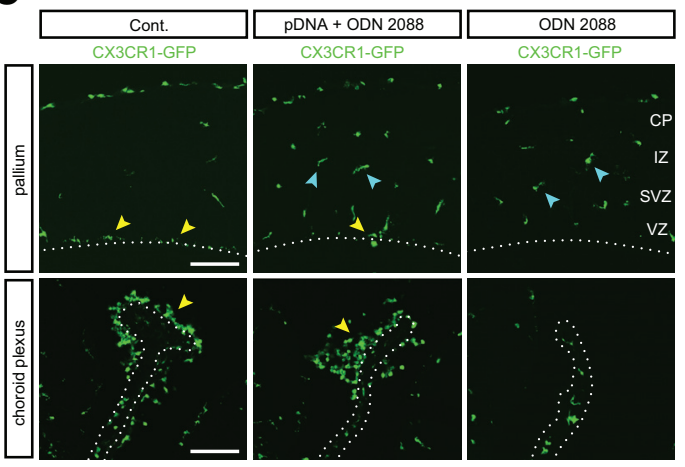

G

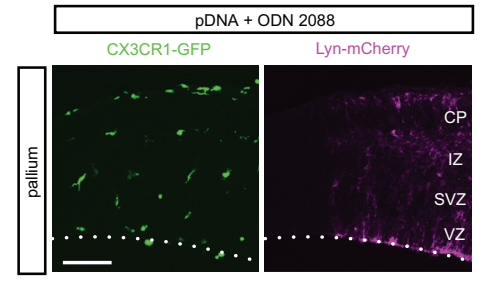

D

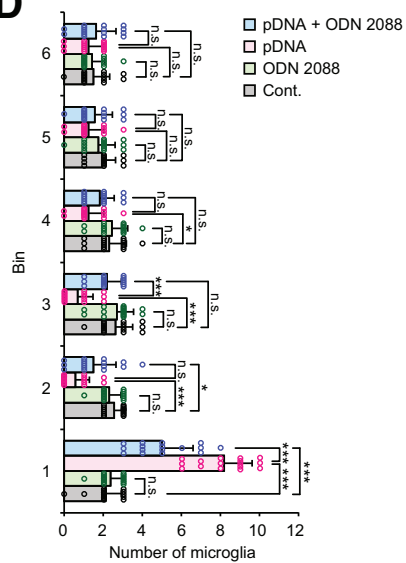

E

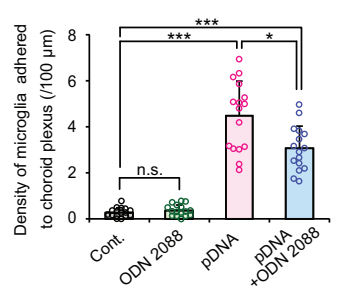

$\mathbf{F}$

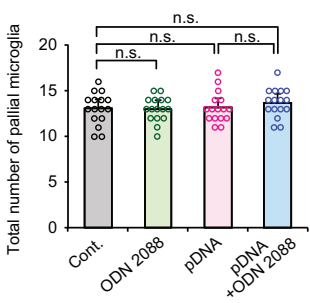

Figure 5. Intraventricular administration of TLR9 antagonist decreases microglial infiltration induced by plasmid DNA injection. A, Relative expression of TLR9 (normalized against GAPDH) in FACS-isolated CX3CR1- and CX3CR1 $1^{+}$cells derived from the cerebral wall of E14 CX3CR1-GFP mice. Data represent mean \pm SD $(n=4$ samples obtained from independent experiments; $p=$ 0.0286, Mann-Whitney $U$ test). B, Experimental design for ODN 2088 treatment. ODN 2088 was injected together with plasmid DNA into the lateral ventricle of E12 CX3CR1-GFP mice, and after $2 \mathrm{~d}$ (E14) the embryonic brains were fixed. C, Immunofluorescence with anti-GFP antibody, showing the distribution of microglia in the pallium and choroid plexus. Yellow arrowheads indicate microglia aberrantly accumulated on the apical surface of the pallium or in the choroid plexus. Cyan arrowheads show microglia which were almost homogenously distributed in the cerebral wall. Scale bar, $100 \mu \mathrm{m}$. $\boldsymbol{D}, \boldsymbol{E}$, Graphs indicate the number of CX3CR1-GFP ${ }^{+}$cells in each $40 \mu \mathrm{m}$ bin of the pallium $(\boldsymbol{D})$ and density of microglia directly adhered to the choroid plexus $(\boldsymbol{E})$, comparing control, only ODN 2088-treated, plasmid DNA-injected, and plasmid DNA + ODN 2088 coinjected brains. $\boldsymbol{F}$, Graph showing the total number of pallial microglia within $240 \mu \mathrm{m}$ from the apical surface. G, Double-immunofluorescence for GFP (CX3CR1) and RFP (Lyn-mCherry) in the cortex of IUE E14 brain treated with ODN 2088. Microglia exhibited a normal distribution pattern in the Lyn-mCherry expressing region where IUE succeeded (Movies 1). Scale bar, $100 \mu \mathrm{m}$. For statistical analyses in $\boldsymbol{D} \boldsymbol{F}, n=16$ samples obtained from eight embryos (2 sections, each) were quantified. Two or three littermates per dam were subjected to a series of tests. Data represent mean \pm SD. $* * * p<0.001, * * p<0.01, * p<0.05$, or n.s., not significant; Steel-Dwass test.

MIP-2, RANTES, and MCP-1] were upregulated in embryonic brains following IUE. Although it remains to be determined whether embryonic microglia in the cortex induce these cytokines and chemokines in response to recognition of plasmid DNA, it is understood that TLR9expressing cells secrete proinflammatory cytokines (such as TNF- $\alpha$, IL-6, and IL-12) on uptake of CpG motifcontaining microbial DNA (Wagner, 2004; Rahmani and Rezaei, 2016). Thus, upregulation of cytokines and chemokines in IUE brains might be induced by TLR9mediated recognition of plasmid DNA.

TNF- $\alpha$ contributes to the proliferation, differentiation, and survival of neural stem/progenitor cells in the brain
(Bernardino et al., 2008; Peng et al., 2008; Lan et al., 2012; Kim et al., 2018). IL-6 promotes differentiation of cortical precursor cells into oligodendrocytes and astrocytes (Bonni et al., 1997; Gruol and Nelson, 1997; Rajan and McKay 1998; Nakanishi et al., 2007; Shigemoto-Mogami et al., 2014), activates adult astrocytes (Campbell et al., 1993), and functions as a neurotrophic and differentiation factor for neurons of the central and peripheral nervous systems (Satoh et al., 1988; Thier et al., 1999; Nakafuku et al., 1992; Murphy et al., 2000; Erta et al., 2012). Therefore, although IUE itself has no effect on apoptosis in neural lineage cells (Zhang et al., 2014; Rosin and Kurrasch, 2018), we cannot exclude the possibility that cyto- 
A

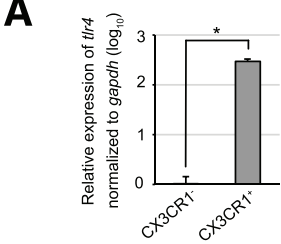

C

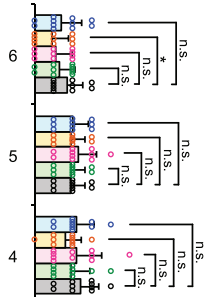

$\stackrel{\complement}{\mathrm{m}}$

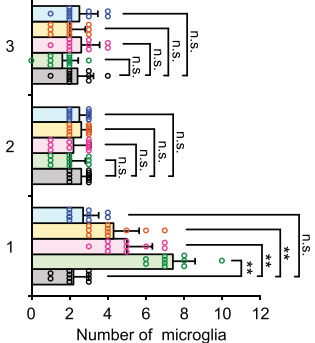

B

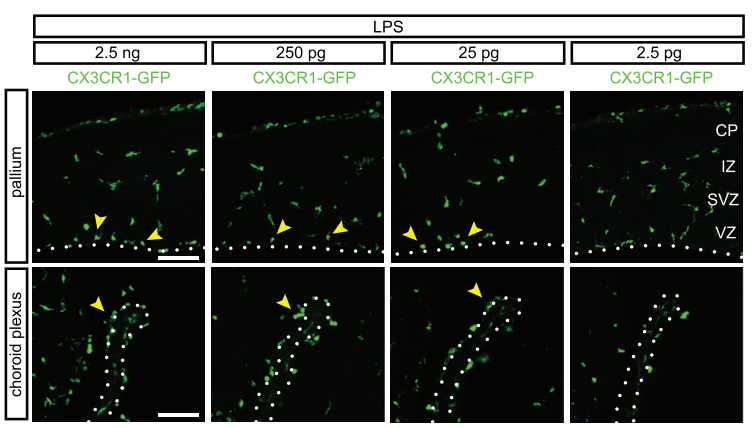

D

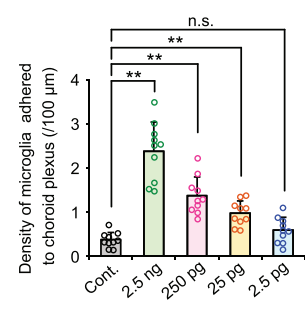

Figure 6. Endotoxins trigger microglial aberrant accumulation. $\boldsymbol{A}$, Relative expression of TLR4 (normalized against GAPDH) in FACS-isolated CX3CR1 ${ }^{-}$and $\mathrm{CX} 3 \mathrm{CR} 1^{+}$cells derived from the cerebral wall of E14 CX3CR1-GFP mice. Data represent mean \pm SD $(n=4$ samples obtained from independent experiments; $p$ $=0.0286$, Mann-Whitney $U$ test). $\boldsymbol{B}, \mathrm{Im}$ munofluorescence with anti-GFP antibody, showing the distribution of microglia in the pallium and choroid plexus in brains injected with the indicated amount of LPS $(2.5 \mathrm{ng}, 250 \mathrm{pg}, 25$ $\mathrm{pg}$, and $2.5 \mathrm{pg}$ ). Yellow arrowheads indicate microglia accumulated near the apical surface of the pallium and on the choroid plexus. Scale bar, $100 \mu \mathrm{m}$. $\boldsymbol{C}, \boldsymbol{D}$, Graphs depicting the number of pallial microglia positioned in each bin (C) and density of microglia adhered to the choroid plexus $(\boldsymbol{D})$ in brains treated with various amounts of LPS. $\boldsymbol{E}$, The total number of pallial microglia within $240 \mu \mathrm{m}$ from the apical surface. For statistical analyses in $\boldsymbol{C}-\boldsymbol{E}, n=10$ samples obtained from five embryos (2 sections, each) were quantified. One or Two littermates per dam were subjected to a series of tests. Data represent mean \pm SD. $* * * p<0.001, * * p<0.01, * p<0.05$, or n.s., not significant; Steel-Dwass test.

Table 6 Statistics for Figure 6

\begin{tabular}{lll}
\hline Graph & Data structure & Type of test \\
Fig. $6 C$, bin 1 & Nonparametric & Steel-Dwass
\end{tabular}

Fig. $6 C$, bin 2

Fig. $6 C$, bin 3

Fig. $6 C$, bin 4

Fig. $6 C$, bin 5

Fig. $6 C$, bin 6

Nonparametric

Nonparametric

Fig. $6 D$

Fig. $6 E$

Nonparametric

Steel-Dwass

Steel-Dwass

Steel-Dwass

Steel-Dwass

Steel-Dwass

Steel-Dwass
Steel-Dwass
Cont vs $2.5 \mathrm{ng}, p=0.0012$;

Cont vs $250 \mathrm{pg}, p=0.0021$; Cont vs $25 \mathrm{pg}, p=0.0055$;

Cont vs $2.5 \mathrm{pg}, p=0.7868$

Cont vs $2.5 \mathrm{ng}, p=0.4164$

Cont vs 250 pg, $p=0.8867$;

Cont vs 25 pg, $p=1.0000$;

Cont vs $2.5 \mathrm{pg}, p=0.9924$

Cont vs 2.5 ng, $p=0.3094$;

Cont vs 250 pg, $p=0.9889$;

Cont vs 25 pg, $p=0.8691$;

Cont vs $2.5 \mathrm{pg}, p=0.9998$

Cont vs 2.5 ng, $p=0.7372$;

Cont vs 250 pg, $p=0.9700$;

Cont vs $25 \mathrm{pg}, p=0.3816$;

Cont vs $2.5 \mathrm{pg}, p=0.9811$

Cont vs $2.5 \mathrm{ng}, p=1.0000$;

Cont vs 250 pg, $p=0.8700$;

Cont vs 25 pg, $p=1.0000$;

Cont vs $2.5 \mathrm{pg}, p=0.9986$

Cont vs 2.5 ng, $p=0.9278$;

Cont vs 250 pg, $p=0.6779$;

Cont vs 25 pg, $p=0.3559$;

Cont vs 2.5 pg, $p=0.9514$

Cont vs 2.5 ng, $p=0.0015$;

Cont vs 250 pg, $p=0.0015$;

Cont vs 25 pg, $p=0.0026$;

Cont vs 2.5 pg, $p=0.5054$

Cont vs $2.5 \mathrm{ng}, p=0.0190$;

Cont vs 250 pg, $p=0.0845$;

Cont vs 25 pg, $p=1.0000$;

Cont vs $2.5 \mathrm{pg}, p=0.9994$ 
A
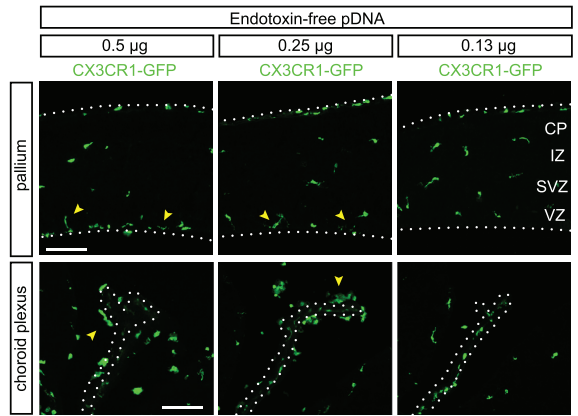

C

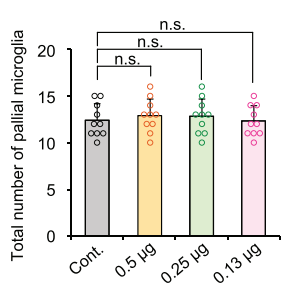

D

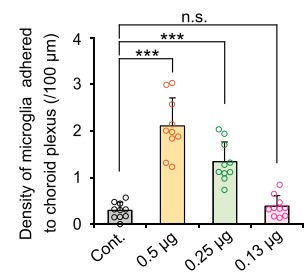

B

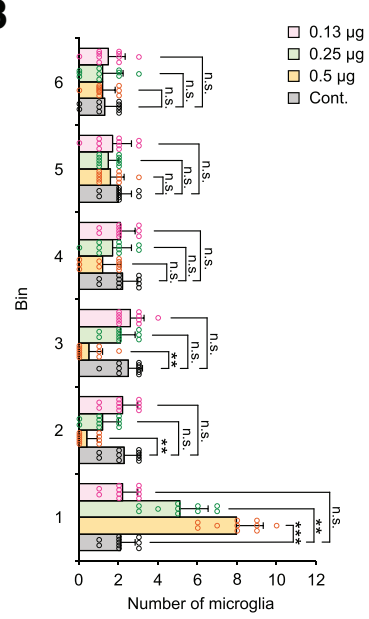

E

Endotoxin-free PDNA $0.5 \mu \mathrm{g}$ ODN $20880.5 \mu \mathrm{g}$

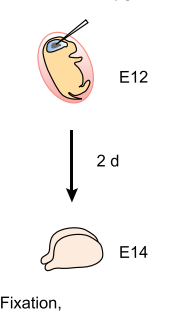

Fixation,
Immunohistochemistry

F

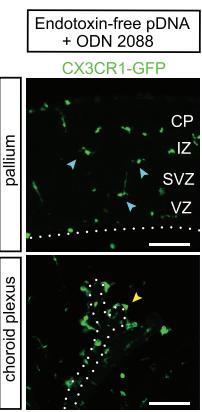

G

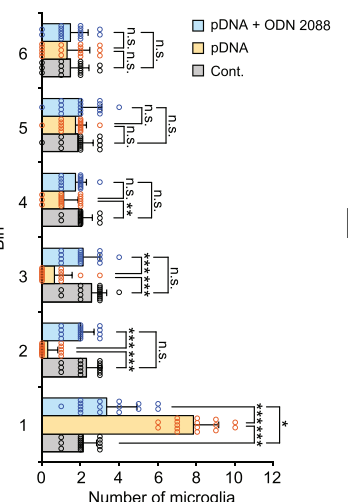

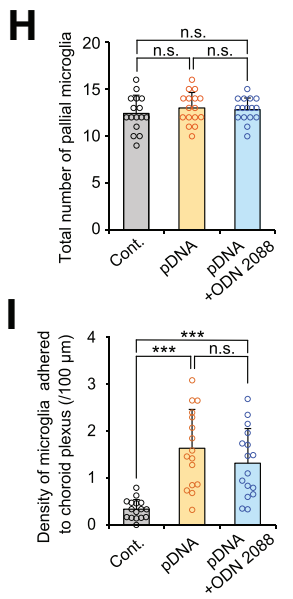

Figure 7. Plasmid DNA itself elicits microglial response via TLR9. A, Immunofluorescence with anti-GFP antibody, showing the distribution of microglia in the pallium and choroid plexus in brains injected with the indicated amount of endotoxin-free plasmid DNA $(0.5,0.25$, and $0.13 \mu \mathrm{g}$ ). Yellow arrowheads show microglia accumulated near the apical surface and on the choroid plexus. Scale bar, $100 \mu \mathrm{m}$. B, C, Graphs depicting the number of pallial microglia positioned in each $40 \mu \mathrm{m}$ bin $(\boldsymbol{B})$ and the total number of these cells within $240 \mu \mathrm{m}$ from the apical surface (C). $\boldsymbol{D}$, Density of microglia adhered to the choroid plexus. For statistical analyses in $\boldsymbol{B}-\boldsymbol{D}, n=10$ samples obtained from five embryos (2 sections, each) were quantified. Two or three littermates per dam were subjected to a series of tests. Data represent mean \pm SD. $* * * p<0.001$, $* * p<0.01, * p<0.05$, or n.s., not significant; Steel-Dwass test (Fig. 7-1). E, Experimental design for administration of ODN 2088 together with endotoxin-free plasmid DNA. $\boldsymbol{F}$, CX3CR1-GFP immunostaining showing microglial distribution in brains injected with endotoxin-free plasmid DNA and ODN 2088 coinjected brains. Yellow arrowhead indicates microglia adhered to the choroid plexus. Cyan arrowheads show microglia which were almost homogenously distributed in the cerebral wall. Scale bar, $100 \mu \mathrm{m}$. $\boldsymbol{G}, \boldsymbol{H}$, Graphs depicting the number of pallial microglia positioned in each bin $(\boldsymbol{G})$ and the total number of these cells within $240 \mu \mathrm{m}$ from the apical surface $(\boldsymbol{H})$. $\boldsymbol{I}$, Density of microglia adhered to the choroid plexus. For statistical analyses in $\mathbf{G}-\boldsymbol{I}, n=16$ samples obtained from eight embryos (2 sections, each) were quantified. Two or three littermates per dam were subjected to a series of tests. Data represent mean \pm SD. $* * * p<0.001, * * p<0.01, * p<0.05$, or n.s. not significant; Steel-Dwass test (Fig. 7-2).

In utero electroporation
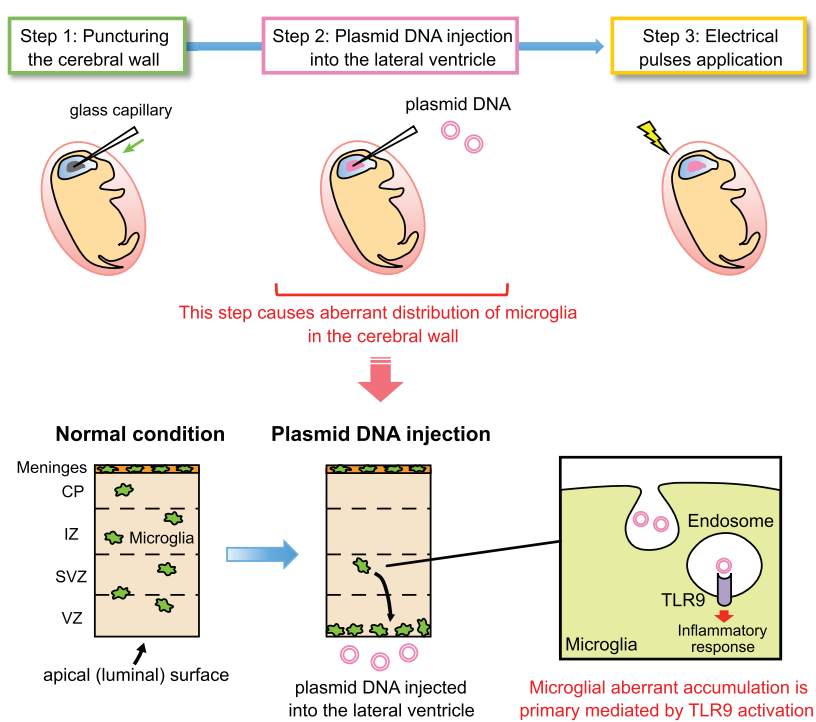

Figure 8. Schematic summary. Schematic illustration showing the mechanism underlying the aberrant distribution of microglia in the cerebral wall of IUE-performed brain. The presence of exogenously derived plasmid DNAs induced microglia to accumulate along the apical surface of the cerebral wall and aggregate in the choroid plexus. This effect was independent of capillary needle puncture of the brain wall, or application of electrical pulses. Such microglial response is mediated by activation of TLR9, which is expressed intracellularly in microglia. 
Table 7 Statistics for Figure 7

\begin{tabular}{|c|c|c|c|}
\hline Graph & Data structure & Type of test & $p$ \\
\hline Fig. $7 B$, bin 1 & Nonparametric & Steel-Dwass & $\begin{array}{l}\text { Cont vs } 0.5 \mu \mathrm{g}, p=7.4 \times 10^{-4} \\
\text { Cont vs } 0.25 \mu \mathrm{g}, p=0.0017 \\
\text { Cont vs } 0.13 \mu \mathrm{g}, p=0.9880\end{array}$ \\
\hline Fig. $7 B$, bin 2 & Nonparametric & Steel-Dwass & $\begin{array}{l}\text { Cont vs } 0.5 \mu \mathrm{g}, p=0.0018 \\
\text { Cont vs } 0.25 \mu \mathrm{g}, p=0.0557 \\
\text { Cont vs } 0.13 \mu \mathrm{g}, p=0.9880\end{array}$ \\
\hline Fig. $7 B$, bin 3 & Nonparametric & Steel-Dwass & $\begin{array}{l}\text { Cont vs } 0.5 \mu \mathrm{g}, p=0.0018 \\
\text { Cont vs } 0.25 \mu \mathrm{g}, p=0.5785 \\
\text { Cont vs } 0.13 \mu \mathrm{g}, p=1.0000\end{array}$ \\
\hline Fig. $7 B$, bin 4 & Nonparametric & Steel-Dwass & $\begin{array}{l}\text { Cont vs } 0.5 \mu \mathrm{g}, p=0.1122 \\
\text { Cont vs } 0.25 \mu \mathrm{g}, p=0.6280 \\
\text { Cont vs } 0.13 \mu \mathrm{g}, p=0.9880\end{array}$ \\
\hline Fig. $7 B$, bin 5 & Nonparametric & Steel-Dwass & $\begin{array}{l}\text { Cont vs } 0.5 \mu \mathrm{g}, p=0.5457 \\
\text { Cont vs } 0.25 \mu \mathrm{g}, p=0.3241 \\
\text { Cont vs } 0.13 \mu \mathrm{g}, p=0.8824\end{array}$ \\
\hline Fig. $7 B$, bin 6 & Nonparametric & Steel-Dwass & $\begin{array}{l}\text { Cont vs } 0.5 \mu \mathrm{g}, p=0.9691 \\
\text { Cont vs } 0.25 \mu \mathrm{g}, p=0.9887 \\
\text { Cont vs } 0.13 \mu \mathrm{g}, p=0.9773\end{array}$ \\
\hline Fig. $7 C$ & Nonparametric & Steel-Dwass & $\begin{array}{l}\text { Cont vs } 0.5 \mu \mathrm{g}, p=0.9011 \\
\text { Cont vs } 0.25 \mu \mathrm{g}, p=0.9593 \\
\text { Cont vs } 0.13 \mu \mathrm{g}, p=0.9994\end{array}$ \\
\hline Fig. $7 D$ & Nonparametric & Steel-Dwass & $\begin{array}{l}\text { Cont vs } 0.5 \mu \mathrm{g}, p=9.0 \times 10^{-4} \\
\text { Cont vs } 0.25 \mu \mathrm{g}, p=9.0 \times 10^{-4} \\
\text { Cont vs } 0.13 \mu \mathrm{g}, p=0.7593\end{array}$ \\
\hline Fig. $7 G$, bin 1 & Nonparametric & Steel-Dwass & $\begin{array}{l}\text { Cont vs pDNA, } p=3.0 \times 10^{-6} \\
\text { pDNA vs. pDNA + ODN } 2088, p=5.2 \times 10^{-6} \\
\text { Cont vs pDNA + ODN } 2088, p=0.0429\end{array}$ \\
\hline Fig. $7 G$, bin 2 & Nonparametric & Steel-Dwass & $\begin{array}{l}\text { Cont vs pDNA, } p=7.0 \times 10^{-6} \\
\text { pDNA vs. pDNA + ODN } 2088, p=1.1 \times 10^{-5} \text {; } \\
\text { Cont vs pDNA + ODN 2088, } p=0.4461\end{array}$ \\
\hline Fig. $7 G$, bin 3 & Nonparametric & Steel-Dwass & $\begin{array}{l}\text { Cont vs pDNA, } p=6.9 \times 10^{-5} \\
\text { pDNA vs. pDNA + ODN 2088, } p=4.3 \times 10^{-4} \\
\text { Cont vs pDNA + ODN } 2088, p=0.2716\end{array}$ \\
\hline Fig. $7 G$, bin 4 & Nonparametric & Steel-Dwass & $\begin{array}{l}\text { Cont vs pDNA, } p=0.0047 \\
\text { pDNA vs. pDNA + ODN 2088, } p=0.0900 \\
\text { Cont vs pDNA + ODN 2088, } p=0.2895\end{array}$ \\
\hline Fig. $7 G$, bin 5 & Nonparametric & Steel-Dwass & $\begin{array}{l}\text { Cont vs pDNA, } p=0.5717 \\
\text { pDNA vs. pDNA + ODN 2088, } p=0.3952 \\
\text { Cont vs pDNA + ODN 2088, } p=0.8520\end{array}$ \\
\hline Fig. $7 G$, bin 6 & Nonparametric & Steel-Dwass & $\begin{array}{l}\text { Cont vs pDNA, } p=0.9469 \\
\text { pDNA vs. pDNA + ODN 2088, } p=0.9472 \\
\text { Cont vs pDNA + ODN 2088, } p=0.9965\end{array}$ \\
\hline Fig. $7 H$ & Nonparametric & Steel-Dwass & $\begin{array}{l}\text { Cont vs pDNA, } p=0.6872 ; \\
\text { pDNA vs. pDNA + ODN 2088, } p=0.9550 \text {; } \\
\text { Cont vs pDNA + ODN 2088, } p=0.7672\end{array}$ \\
\hline Fig. $7 I$ & Nonparametric & Steel-Dwass & $\begin{array}{l}\text { Cont vs pDNA, } p=2.6 \times 10^{-5} \\
\text { pDNA vs. pDNA + ODN 2088, } p=0.5896 \text {; } \\
\text { Cont vs pDNA + ODN 2088, } p=9.2 \times 10^{-5}\end{array}$ \\
\hline
\end{tabular}

kines produced by microglia expressing TLR9 could modify the physiologic environment in IUE brain.

We showed that exposure to as little as $25 \mathrm{pg}$ of intraventricular LPS (a smaller amount than that contained in plasmid DNA solutions purified with the QIAGEN plasmid Maxi Kit) could attract microglia toward the apical surface. Importantly, although ODN 2088 coadministration coupled with endotoxin-free plasmid DNAs restored microglial aberrant distribution, it did not completely inhibit microglial aggregation in the choroid plexus, indicating that other molecular mechanisms might function for sensing plasmid DNAs. Previous studies revealed that double-stranded DNA complexed with cationic liposomes can induce type I interferon independently of CpG motifs in mouse embryonic fibroblasts and HEK293 cells, which do not express TLR9 (Ishii et al., 2006; Shirota et al., 2006). Recently, Takaoka et al. (2007) reported a cytoplasmic DNA sensor, DNA-dependent activator of IFNregulatory factors (DAl), that recognizes double-stranded DNA and activates innate immune responses independently of TLR9. Further studies are required to elucidate whether a TLR9-independent immune response to plasmid DNA occurs in microglia.

In summary, intraventricular plasmid DNA injection, a procedure essential for standard IUE techniques, can induce abnormal microglial behaviors in developing cortical walls. These abnormalities can be partly prevented by application of the TLR9 antagonist ODN2088. Overall, 
our findings emphasize that studies of embryonic microglia following IUE should be interpreted with caution.

\section{References}

Ahmad-Nejad P, Häcker H, Rutz M, Bauer S, Vabulas RM, Wagner H (2002) Bacterial CpG-DNA and lipopolysaccharides activate tolllike receptors at distinct cellular compartments. Eur J Immunol 32:1958-1968. CrossRef Medline

Akira S, Takeda K (2004) Toll-like receptor signalling. Nat Rev Immunol 4:499-511.

Arnò B, Grassivaro F, Rossi C, Bergamaschi A, Castiglioni V, Furlan R, Greter M, Favaro R, Comi G, Becher B, Martino G, Muzio L (2014) Neural progenitor cells orchestrate microglia migration and positioning into the developing cortex. Nat Commun 5:5611.

Ashwell K (1991) The distribution of microglia and cell death in the fetal rat forebrain. Dev Brain Res 58:1-12. Medline

Barger N, Keiter J, Kreutz A, Krishnamurthy A, Weidenthaler C, Martínez-Cerdeño V, Tarantal AF, Noctor SC (2018) Microglia: an intrinsic component of the proliferative zones in the fetal rhesus monkey (Macaca mulatta) cerebral cortex. Cereb Cortex. Advance online publication. Retrieved July 10, 2018. doi: 10.1093/cercor/ bhy145.

Barton GM, Kagan JC, Medzhitov R (2006) Intracellular localization of Toll-like receptor 9 prevents recognition of self DNA but facilitates access to viral DNA. Nat Immunol 7:49-56. CrossRef Medline

Bauer S, Kirschning CJ, Häcker H, Redecke V, Hausmann S, Akira S, Wagner H, Lipford GB (2001) Human TLR9 confers responsiveness to bacterial DNA via species-specific CpG motif recognition. Proc Natl Acad Sci U S A 98:9237-9242. CrossRef Medline

Bernardino L, Agasse F, Silva B, Ferreira R, Grade S, Malva JO (2008) Tumor necrosis factor-alpha modulates survival, proliferation, and neuronal differentiation in neonatal subventricular zone cell cultures. Stem Cells 26:2361-2371. CrossRef Medline

Bonni A, Sun Y, Nadal-Vicens M, Bhatt A, Frank DA, Rozovsky I, Stahl N, Yancopoulos GD, Greenberg ME (1997) Regulation of gliogenesis in the central nervous system by the JAK-STAT signaling pathway. Science 278:477-483. CrossRef

Butchi NB, Woods T, Du M, Morgan TW, Peterson KE (2011) TLR7 and TLR9 trigger distinct neuroinflammatory responses in the CNS. Am J Pathol 179:783-794. CrossRef Medline

Campbell IL, Abraham CR, Masliah E, Kemper P, Inglis JD, Oldstone MB, Mucke L (1993) Neurologic disease induced in transgenic mice by cerebral overexpression of interleukin 6. Proc Natl Acad Sci U S A 90:10061-10065. Medline

Cho KO, Hsieh J (2016) Microglial TLR9: guardians of homeostatic hippocampal neurogenesis. Epilepsy Curr 16:39-40. CrossRef Medline

Chockalingam A, Brooks JC, Cameron JL, Blum LK, Leifer CA (2009) TLR9 traffics through the Golgi complex to localize to endolysosomes and respond to CpG DNA. Immunol Cell Biol 87:209-217. CrossRef Medline

Christensen LB, Woods TA, Carmody AB, Caughey B, Peterson KE (2014) Age-related differences in neuroinflammatory responses associated with a distinct profile of regulatory markers on neonatal microglia. J Neuroinflammation 11:70.

Cunningham CL, Martínez-Cerdeño V, Noctor SC (2013) Microglia regulate the number of neural precursor cells in the developing cerebral cortex. J Neurosci 33:4216-4233. CrossRef

Doi Y, Mizuno T, Maki Y, Jin S, Mizoguchi H, Ikeyama M, Doi M, Michikawa M, Takeuchi H, Suzumura A (2009) Microglia activated with the toll-like receptor 9 ligand $\mathrm{CpG}$ attenuate oligomeric amyloid $\beta$ neurotoxicity in in vitro and in vivo models of Alzheimer's disease. Am J Pathol 175:2121-2132. CrossRef Medline

Erta M, Quintana A, Hidalgo J (2012) Interleukin-6, a major cytokine in the central nervous system. Int J Biol Sci 8:1254-1266. CrossRef Medline

Fukuchi-Shimogori T, Grove EA (2001) Neocortex patterning by the secreted signaling molecule FGF8. Science 294:1071-1074. CrossRef Medline
Gruol DL, Nelson TE (1997) Physiological and pathological roles of interleukin-6 in the central nervous system. Mol Neurobiol 15:307339. CrossRef Medline

Hattori Y, Miyata T (2018) Microglia extensively survey the developing cortex via the CXCL12/CXCR4 system to help neural progenitors to acquire differentiated properties. Genes Cells 23:915-922. CrossRef Medline

Hemmi H, Takeuchi O, Kawai T, Kaisho T, Sato S, Sanjo H, Matsumoto M, Hoshino K, Wagner H, Takeda K, Akira S (2000) A Toll-like receptor recognizes bacterial DNA. Nature 408:740-745. CrossRef Medline

Ishii KJ, Coban C, Kato H, Takahashi K, Torii Y, Takeshita F, Ludwig H, Sutter G, Suzuki K, Hemmi H, Sato S, Yamamoto M, Uematsu S, Kawai T, Takeuchi O, Akira S (2006) A toll-like receptorindependent antiviral response induced by double-stranded B-form DNA. Nat Immunol 7:40-48. CrossRef Medline

Jung S, Aliberti J, Graemmel P, Sunshine MJ, Kreutzberg GW, Sher A, Littman DR (2000) Analysis of Fractalkine Receptor CX3CR1 function by targeted deletion and green fluorescent protein reporter gene insertion. Mol Cell Biol 20:4106-4114. CrossRef

Kim M, Jung K, Kim IS, Lee IS, Ko Y, Shin JE, Park KI (2018) TNF- $\alpha$ induces human neural progenitor cell survival after oxygen-glucose deprivation by activating the NF- $\kappa$ B pathway. Exp Mol Med 50:14. CrossRef Medline

Krieg AM, Yi AK, Matson S, Waldschmidt TJ, Bishop GA, Teasdale R, Koretzky GA, Klinman DM (1995) CpG motifs in bacterial DNA trigger direct B-cell activation. Nature 374:546-549. CrossRef Medline

Kumagai Y, Takeuchi O, Akira S (2008) TLR9 as a key receptor for the recognition of DNA. Adv Drug Deliv Rev 60:795-804. CrossRef Medline

Lan X, Chen Q, Wang Y, Jia B, Sun L, Zheng J, Peng H (2012) TNF- $\alpha$ affects human cortical neural progenitor cell differentiation through the autocrine secretion of leukemia inhibitory factor. PLoS One 7:e50783. CrossRef Medline

Matsuda T, Murao N, Katano Y, Juliandi B, Kohyama J, Akira S, Kawai T, Nakashima K (2015) TLR9 signalling in microglia attenuates seizure-induced aberrant neurogenesis in the adult hippocampus. Nat Commun 6:6514.

Miyata T, Kawaguchi A, Saito K, Kawano M, Muto T, Ogawa M (2004) Asymmetric production of surface-dividing and non-surfacedividing cortical progenitor cells. Development 131:3133-3145. CrossRef Medline

Monier A, Adle-Biassette H, Delezoide AL, Evrard P, Gressens P, Verney C (2007) Entry and distribution of microglial cells in human embryonic and fetal cerebral cortex. J Neuropathol Exp Neurol 66:372-382. CrossRef Medline

Murphy PG, Borthwick LA, Altares M, Gauldie J, Kaplan D, Richardson PM (2000) Reciprocal actions of interleukin-6 and brainderived neurotrophic factor on rat and mouse primary sensory neurons. Eur J Neurosci 12:1891-1899. Medline

Nakafuku M, Satoh T, Kaziro Y (1992) Differentiation factors, including nerve growth factor, fibroblast growth factor, and interleukin-6, induce an accumulation of an active Ras.GTP complex in rat pheochromocytoma PC12 cells. J Biol Chem 267:19448-19454. Medline

Nakanishi M, Niidome T, Matsuda S, Akaike A, Kihara T, Sugimoto H (2007) Microglia-derived interleukin-6 and leukaemia inhibitory factor promote astrocytic differentiation of neural stem/progenitor cells. Eur J Neurosci 25:649-658. CrossRef Medline

Nimmerjahn A, Kirchhoff F, Helmchen F (2005) Resting microglial cells are highly dynamic surveillants of brain parenchyma in vivo. Science 308:1314-1318. CrossRef Medline

O'Neill LA, Golenbock D, Bowie AG (2013) The history of Toll-like receptors: redefining innate immunity. Nat Rev Immunol 13:453460. CrossRef Medline

Okamoto M, Namba T, Shinoda T, Kondo T, Watanabe T, Inoue $\mathrm{Y}$, Takeuchi K, Enomoto Y, Ota K, Oda K, Wada Y, Sagou K, Saito K, Sakakibara A, Kawaguchi A, Nakajima K, Adachi T, Fujimori T, Ueda M, Hayashi S, et al. (2013) TAG-1-assisted progenitor elon- 
gation streamlines nuclear migration to optimize subapical crowding. Nat Neurosci 16:1556-1566. CrossRef Medline

Peng H, Whitney N, Wu Y, Tian C, Dou H, Zhou Y, Zheng J (2008) HIV-1-infected and/or immune-activated macrophage-secreted TNF-alpha affects human fetal cortical neural progenitor cell proliferation and differentiation. Glia 56:903-916. CrossRef Medline

Perry VH, Hume DA, Gordon S (1985) Immunohistochemical localization of macrophages and microglia in the adult and developing mouse brain. Neuroscience 15:313-326. Medline

Rahmani F, Rezaei N (2016) Therapeutic targeting of Toll-like receptors: a review of Toll-like receptors and their signaling pathways in psoriasis. Expert Rev Clin Immunol 12:1289-1298. CrossRef Medline

Rajan P, McKay RD (1998) Multiple routes to astrocytic differentiation in the CNS. J Neurosci 18:3620-3629. Medline

Rosin JM, Kurrasch DM (2018) In utero electroporation induces cell death and alters embryonic microglia morphology and expression signatures in the developing hypothalamus. J Neuroinflammation 15:181.

Saito T, Nakatsuji N (2001) Efficient gene transfer into the embryonic mouse brain using in vivo electroporation. Dev Biol 240:237-246. CrossRef Medline

Satoh T, Nakamura S, Taga T, Matsuda T, Hirano T, Kishimoto T, Kaziro Y (1988) Induction of neuronal differentiation in PC12 cells by B-cell stimulatory factor 2/interleukin 6 . Mol Cell Biol 8:35463549. Medline

Scholtzova H, Do E, Dhakal S, Sun Y, Liu S, Mehta PD, Wisniewski T (2017) Innate immunity stimulation via Toll-like receptor 9 ameliorates vascular amyloid pathology in Tg-SwDI Mice with associated cognitive benefits. J Neurosci 37:936-959. CrossRef Medline

Shigemoto-Mogami Y, Hoshikawa K, Goldman JE, Sekino Y, Sato K (2014) Microglia enhance neurogenesis and oligodendrogenesis in the early postnatal subventricular zone. J Neurosci 34:2231-2243. CrossRef Medline

Shinoda T, Nagasaka A, Inoue Y, Higuchi R, Minami Y, Kato K, Suzuki M, Kondo T, Kawaue T, Saito K, Ueno N, Fukazawa Y, Nagayama M, Miura T, Adachi T, Miyata T (2018) Elasticity-based boosting of neuroepithelial nucleokinesis via indirect energy transfer from mother to daughter. PLoS Biol 16:e2004426.

Shirota H, Ishii KJ, Takakuwa H, Klinman DM (2006) Contribution of interferon-beta to the immune activation induced by doublestranded DNA. Immunology 118:302-310. CrossRef Medline
Squarzoni P, Oller G, Hoeffel G, Pont-Lezica L, Rostaing P, Low D, Bessis A, Ginhoux F, Garel S (2014) Microglia modulate wiring of the embryonic forebrain. Cell Rep 8:1271-1279. CrossRef Medline

Stunz LL, Lenert P, Peckham D, Yi AK, Haxhinasto S, Chang M, Krieg AM, Ashman RF (2002) Inhibitory oligonucleotides specifically block effects of stimulatory CpG oligonucleotides in B cells. Eur J Immunol 32:1212-1222. CrossRef

Swinnen N, Smolders S, Avila A, Notelaers K, Paesen R, Ameloot M, Brône B, Legendre P, Rigo JM (2013) Complex invasion pattern of the cerebral cortex bymicroglial cells during development of the mouse embryo. Glia 61:150-163. CrossRef Medline

Tabata H, Nakajima K (2001) Efficient in utero gene transfer system to the developing mouse brain using electroporation: visualization of neuronal migration in the developing cortex. Neuroscience 103: 865-872.

Takaoka A, Wang Z, Choi MK, Yanai H, Negishi H, Ban T, Lu Y, Miyagishi M, Kodama T, Honda K, Ohba Y, Taniguchi T (2007) DAI (DLM-1/ZBP1) is a cytosolic DNA sensor and an activator of innate immune response. Nature 448:501-505. CrossRef Medline

Takeshita F, Leifer CA, Gursel I, Ishii KJ, Takeshita S, Gursel M, Klinman DM (2001) Cutting edge: role of Toll-like receptor 9 in CpG DNA-induced activation of human cells. J Immunol 167:35553558. Medline

Takeuchi O, Akira S (2010) Pattern recognition receptors and inflammation. Cell 140:805-820. CrossRef Medline

Thier M, März P, Otten U, Weis J, Rose-John S (1999) Interleukin-6 (IL-6) and its soluble receptor support survival of sensory neurons. J Neurosci Res 55:411-422. CrossRef Medline

Thion MS, Garel S (2017) On place and time: microglia in embryonic and perinatal brain development. Curr Opin Neurobiol 47:121-130. CrossRef Medline

Vijay K (2018) Toll-like receptors in immunity and inflammatory diseases: past, present, and future. Int Immunopharmacol 59:391412. CrossRef Medline

Wagner $\mathrm{H}$ (2004) The immunobiology of the TLR9 subfamily. Trends Immunol 25:381-386. CrossRef Medline

Zhang P, Yan Z, Wu C, Niu L, Liu N, Xu R (2014) Three puncture sites used for in utero electroporation show no significantly different negative impacts during gene transfer into the embryonic mouse brain. Neurosci Lett 578:176-181. CrossRef Medline 